FKIP Universitas PGRI Banyuwangi Seminar Nasional

\title{
TOPONOMI KECAMATAN BANYUWANGI, SINGOJURUH, DAN ROGOJAMPI
}

\author{
Agus Mursidi ${ }^{1}$, Dhalia Soetopo ${ }^{2}$ \\ Fakultas Keguruan dan Ilmu Pendidikan, Universitas PGRI Banyuwangi ${ }^{1}$ \\ Email :agusmursidi78@gmail.com \\ Fakultas Keguruan dan Ilmu Pendidikan, Universitas PGRI Banyuwangi ${ }^{2}$ \\ Email :dhalia.soetopo@gmail.com
}

\begin{abstract}
Cabang ilmu yang mempelajari penamaan tempat disebut dengan toponimi. Penelitian Toponimi memberikan kontribusi besar terhadap pemahaman sejarah pada masyarakat dan memberikan sistem referensi geografis yang sangat berguna di masyarakat. Kabupaten Banyuwangi memiliki wilayah yang relatif unik karena terdiri dari wilayah pantai/laut, dataran dan gunung. Penduduknya memiliki keragaman etnis yaitu Osing (etnis asli Banyuwangi), Jawa, Madura, Bugis dan Bali. Hal ini menjadi indikasi penamaan tempat yang memiliki karakteristik tersendiri.

Penelitian dilakukan dengan metode deskriptif yang dilakukan dengan Tahapan penelitian yang direncanakan adalah tahap I kajian toponomi 24 kecamatan. Pengambilan dilakukan dengan wawancara terhadap 3 nara sumber. Wawancara pertama dilakukan dengan pihak pemerintah setempat. Selanjutnya, 2 tokoh masyarakat dipilih berdasarkan informasi yang didapat dari pemerintah setempat. Wawancara dilakukan oleh 2 tim dimana 1 peneliti didampingi 1 tenaga survei. Proses wawancara dilengkapi dengan alat perekam dan dokumentasi menggunakan kamera. Informasi hasil wawancara selanjutnya disusun dalam bentuk kategori dan dianalisis menggunakan metode triangulasi.
\end{abstract}

\section{Keywords : Toponomi, Masyarakat, Banyuwangi, Singojuruh, Rogojampi}

\begin{abstract}
Abstrack
The branch of science that studies the naming of places is called toponimi. Toponimi's research contributes greatly to the historical understanding of society and provides a very useful geographic reference system in society. Banyuwangi Regency has a relatively unique area because it consists of coastal / marine, terrain and mountain areas. Its inhabitants have ethnic diversity namely Osing (Banyuwangi original ethnic), Java, Madura, Bugis and Bali. This is an indication of the naming of places that have their own characteristics.

The research was done by descriptive method which was done with the research phases which is planned is phase I of toponomic study of 24 districts. The taking is done by interviewing 3 resource persons. The first interview was conducted with the local government. Furthermore, two community leaders were selected based on information obtained from the local government. The interview was conducted by 2 teams in which 1 researcher was accompanied by 1 surveyor. The interview process is equipped with a tape recorder and documentation using a camera. Information on the results of interviews will then be organized into categories and analyzed using triangulation method.
\end{abstract}

Keywords: Toponomi, Masyarakat, Banyuwangi, Singojuruh, Rogojampi 


\section{FKIP Universitas PGRI Banyuwangi Seminar Nasional}

\section{Pendahuluan}

Studi pemberian suatu nama sangat penting untuk mempelajari masa lalu sebuah komunitas masyarakat atau suatu negara. Studi penamaan tempat (toponimi) merupakan riset yang membedakan masa lampau dari segi bahasa, arkeologi dan sejarah. Cabang ilmu yang mempelajari penamaan tempat disebut dengan toponimi. Penelitian toponimi memberikan kontribusi besar terhadap pemahaman sejarah pada masyarakat. Toponimi mengungkap identitas masyarakat, sejarah, sosial, dan hubungan politik. Toponomi memberikan sistem referensi geografis yang sangat berguna di masyarakat. Konsistensi dan akurasi hasil penelitian toponomi suatu tempat sangat penting untuk menghindarkan kesalahan pemahaman di masyarakat (OwuEwie C, 2014).

Penamaan tempat bertujuan untuk menggali peranan penamaan di masa lalu dan peran pembentukan identitas daerah. Tempat dan penamaannya memiliki hubungan yang erat sebagai bentuk refleksi atau faktor yang menumbuhkan perasaan individu atau komunitas. Identitas dalam hal ini adalah identitas personal, etnis, tempat dan sebagainya.

Penamaan tempat memberikan perasaan memiliki terhadap suatu area dan kelompok social yang menghuninya. Seseorang yang tinggal di suatu tempat, menjadi akrab dengan lingkungan pada tahap awal dan mebangun ikatan dengan tempat tinggalnya. Jika orang tersebut pindah tempat tinggal maka secara bertahap akan membentuk ikatan dengan tempat tinggal baru (Helleland B, 2012).

Salah satu tren utama dalam pengembangan toponomi modern adalah studi yang tidak hanya mempelajari nama-nama tempat secara individual tetapi sistem toponomi daerah secara holistik. Sistem toponimi wilayah merupakan kombinasi natural dari namanama geografis yang berada di sebuah territorial yang dengan cara tertentu berkaitan dengan obyek-obyek yang mendasari penamaan. Salah satu masalah penting dalam kehidupan di abad 21 adalah perlindungan sumber daya alam, studi perubahan wilayah, dan secara khusus penyebaran spesies flora dan fauna pada periode sejarah yang berbeda (Atasoy E, Yeginbayeva A, 2017).

Penelitian toponomi telah banyak dilakukan untuk penamaan tempat seperti desa di Sumedang (Nurhasanah et al, 2014), desa di Yogyakarta (Prihadi, 2015b), kampung di wilayah keraton Surakarta (Priyomarsono MW, 2012), kampung di Kotagede Yogyakarta (Istiana, 2012), kelurahan di kota Probolinggo (Roesmawati A, 2013), distrik (Grillo H, 2015), wilayah etnis (Aleru JO, Alebi RA, 2010; Zakharova E, 2015), pemukiman Tepe Hungaria (Győrffy E, 2015), wilayah perbukitan Aravalli and Semi-Arid Plains of Rajasthan di India (Singh V, Kumari L, 2016), wilayah Catalunya, Spanyol (Curchin LA, 2011), toponimi kepulauan (Yulius, Triyono, 2011), toponimi selat (Yulius, Salim HWL, 2014), pulau-pulau di Pasifik (Martinez JIB, Pineda CS, 2016), toponimi kabupaten Lamongan (Camalia 
M, 2015), propinsi (Sujatna ETS et al, 2016), dan toponomi negara (Bugybaykizi BZ, et al, 2015). Penelitian toponimi dari segi bahasa antara lain bahasa Aramaic di Lebanon (Wardini E, 2012), pedusunan (kampung) di Yogyakarta (Prihadi, 2015a), serta toponomi pulau dan tanjung dari segi bahasa Perancis (Fleury C, Raoulx B, 2016). Penelitian juga dilakukan dari sudut pandang sejarah yaitu nama jalan di Medan (Ginting DA, 2009), tempat dan jalan di Spanyol (Nicolae I, 2010), jalan di Taipei (Huang W, 2011), toponimi di Afrika (Batoma A, 2006), toponimi Korea (Ryu J-H, 2012), daerah Fante di Ghana Selatan (Owu-Ewie C, 2014), dan Danube di Eropa (Enica S, 2016).

Kabupaten Banyuwangi merupakan kota di ujung timur pulau Jawa dengan luas wilayah 5.782,50 km2. Banyuwangi terbagi menjadi 24 kecamatan dan 217 desa/kelurahan (Badan Pusat Statistik kabupaten Banyuwangi, 2013). Kondisi geografis meliputi selat Bali yang merupakan batas dengan propinsi Bali di sisi timur, dataran rendah sebagai lahan pertanian dan ladang di wilayah bagian utara dan selatan, serta daerah dataran tinggi (gunung Ijen dan gunung Raung) di sisi barat sebagai lahan perkebunan. Selain itu, Banyuwangi merupakan pusat kerajaan berdasarkan sejarah lokal yaitu kerajaan Blambangan pada masa-masa Majapahit. Latar belakang ini akan berpengaruh pada toponimi kecamatan dan desa/kelurahan yang ada.

2. Kajian Literatur dan Pengembangan Hipotesis
Toponimi wilayah Catalunya, Spanyol menunjukkan aspek sejarah Iberian, Yunani dan Latin (Curchin LA, 2011). Toponimi kabupaten Lamongan berasal dari unsur sejarah dimana hal ini sangat berkaitan dengan sosok yang bernama Hadi, murid Sunan Giri yang ditugaskan untuk membimbing dan memimpin masyarakat Lamongan (Camalia M, 2015).

Penelitian toponomi Kazakhtan dilakukan berdasarkan aspek etnografi yang dapat memberikan data pada aspek sejarah dan budaya spiritual masyarakat yang nomaden (Bugybaykizi BZ, et al, 2015).

Nama jalan di Medan awalnya adalah namanama Belanda, Cina, dan India. Setelah kemerdekaan diganti berdasarkan nama tokoh pejuang, pendidikan dan lain-lain (Ginting DA, 2009). Toponomi tempat dan jalan di Camino De Santiago, Spanyol bagian utara merefleksikan berkembangnya usia populasi yaitu lingkungan alam dan sosial masyarakat (Nicolae I, 2010). Toponimi jalan di Taipei dipengaruhi oleh aspek sejarah dimana tergantung pada situasi politik dan kekuasaan (Huang W, 2011). Toponomi wilayah Yoruba di Nigeria bagian Tenggara sangat dipengaruhi unsur budaya masyarakat dan rangkaian peristiwa sejarah (Aleru JO, Alebi RA, 2010). Toponimi wilayah Lebanon sangat dipengaruhi bahasa Aramaic dimana terjadi perubahan dari tipe Western menjadi tipe Modern West Aramaic (Wardini E, 2012). Toponomi wilayah Obonezh'e Timur di Rusia bagian utara dipengaruhi masa sejarah dengan tahapan dan alur pemanfataan lahan. 
Penamaan menunjukkan interaksi antara budaya dan bahasa dari etnis yang mendiami wilayah tersebut (Zakharova E, 2015). Toponomi destinasi wisata di Jawa Barat terdiri dari 3 tipe penamaan yaitu satu kata benda nama diri (proper noun), 2 kata (generic noun + proper noun), dan 3 suku kata (Sujatna ETS et al, 2016). Survei di Kepulauan Togean Kabupaten Tojo UnaUna Provinsi Sulawesi Tengah berhasil mengindentifikasi sebanyak 211 pulau dengan 210 pulau tidak terdaftar di Departemen Dalam Negeri, dan hanya 1 pulau yang mempunyai nama.

Penamaan pulau oleh masyarakat didasarkan pada karakter fisik pulau, karakter biologi, orang yang pertama menempati pulau, kisah yang terjadi, pemanfaatan dan posisi pulau (Yulius, Triyono, 2011). Toponimi pulau-pulau Mexico di Pasifik dipengaruhi oleh era-era sejarah yang mengacu kondisi alam dan masyarakatnya (Martinez JIB, Pineda CS, 2016), Toponimi selat di kepulauan Riau berdasarkan pada bentuk topografi, flora, fauna, bentuk dan posisi selat, sejarah dan suku bangsa (Yulius, Salim HWL, 2014). Toponomi pulau dan tanjung dari segi bahasa Perancis menunjukkan pengaruh sejarah dan budaya setempat dimana masyarakat cenderung tidak membedakan sebuah tanjung dengan sebuah pulau. Hal ini disebabkan kondisi geografis sebuah tanjung yang mirip sebuah pulau (Fleury C, Raoulx B, 2016).

Toponimi di Afrika dipengaruhi faktor geografi, sejarah, bahasa, simbolik, dan sosio-politik (Batoma A, 2006). Toponimi Korea sangat dipengaruhi masa kemerdekaan pasca penjajahan Jepang. Penamaan asli masyarakat banyak yang hilang dari percakapan sehari-hari pasca urbanisasi industri di era 1980-an (Ryu $\mathrm{J}-\mathrm{H}, 2012$ ). Hasil penelitian daerah hunian Fante di Ghana Selatan menunjukkan pola kata tunggal, gabungan, afiksasi, dan perulangan. Penamaan tempat ini memiliki fungsi pernyataan, interogatif atau imperatif, dengan struktur kata yang sederhana, gabungan, atau kalimat kompleks (OwuEwie C, 2014). Toponimi wilayah Danube di Eropa sangat dipengaruhi budaya Romawi dan perpaduannya dengan etnis-etnis lainnya (Enica S, 2016).

\subsection{Toponimi}

Kata toponimi berasal dari bahasa Yunani yaitu topos dan onmya yang berarti "tempat" dan "nama". Toponomi dalam hal ini berarti pemberian nama dengan mengacu pada fitur topografi. Penamaan tempat ini banyak dilakukan untuk daerah tempat tinggal seperti kota besar, kota, desa, dusun, atau area pertanian. Dari sudut pandang teoritis, toponomi memberikan informasi berkaitan dengan kondisi geografis, budaya, dan sejarah suatu tempat serta hubungan masyarakat yang mendiaminya. Hal ini disebabkan karena pertimbangan masyarakat dalam pemberian nama tempat tersebut. Penamaan tempat tidak hanya berdasarkan sifat fisik daerah tetapi juga karena peristiwa sejarah lokal, etnis, sumber cerita atau agama, dan peristiwa jenaka (Ryu J-H, 2012).

Toponimi merupakan materi dan secara metafora menghubungkan aspek geografi 
dan bahasa dari segi substansi dan simbolik secara bersamaan. Toponimi dibaca, diperbincangkan, dipetakan, dikatalogkan, dan ditulis setiap hari secara khusus dan resmi di rambu jalan, nama jalan, dan alamat-alamat. Menyebar melalui bahasa, toponimi berkembang di sejarah, cerita rakyat, norma-norma sosial, dan kepercayaan. Toponimi mengikat hal-hal ini pada suatu tempat. Kajian toponimi dapat menjadi jendela bagi pengetahuan yang detil dan perasaan turut memiliki akan suatu tempat. Kajian toponimi membutuhkan pertanyaanpertanyaan terkait politik, budaya, lokasi dan identitas.

\subsection{Kabupaten Banyuwangi}

Kabupaten Banyuwangi, terletak di ujung paling Timur pulau Jawa dan berbatasan langsung dengan kabupaten Situbondo di utara, selat Bali di Timur, samudra Hindia di selatan serta kabupaten Jember dan kabupaten Bondowoso di barat. Pelabuhan Ketapang menghubungkan pulau Jawa di Banyuwangi dengan pelabuhan Gilimanuk di Bali. Secara geografis, Banyuwangi terletak di daerah wisata alam yang masih hijau dan liar layaknya safari di Afrika, di tambah juga dengan lokasinya yang dekat dengan Samudra Hindia.

Kabupaten Banyuwangi berjarak 239 km sebelah timur Surabaya, dan dihuni oleh beragam suku bangsa. Mayoritas penduduk lokal Banyuwangi adalah suku Osing yang dipercaya merupakan sub-suku Jawa, dan suku lain yang hidup dengan damai seperti, suku Madura, suku Jawa, Bali dan Bugis. Dalam keseharian, penduduk lokal memakai bahasa Osing, yang merupakan ragam tertua bahasa Jawa tapi berdasarkan kebudayaan, budaya suku Osing banyak dipengaruhi oleh budaya Bali (Anonim, 2014).

Nama-nama 24 kecamatan dan letak ketinggian gegografis di Banyuwangi adalah sebagai berikut:

Tabel 1. Tinggi wilayah di Banyuwangi
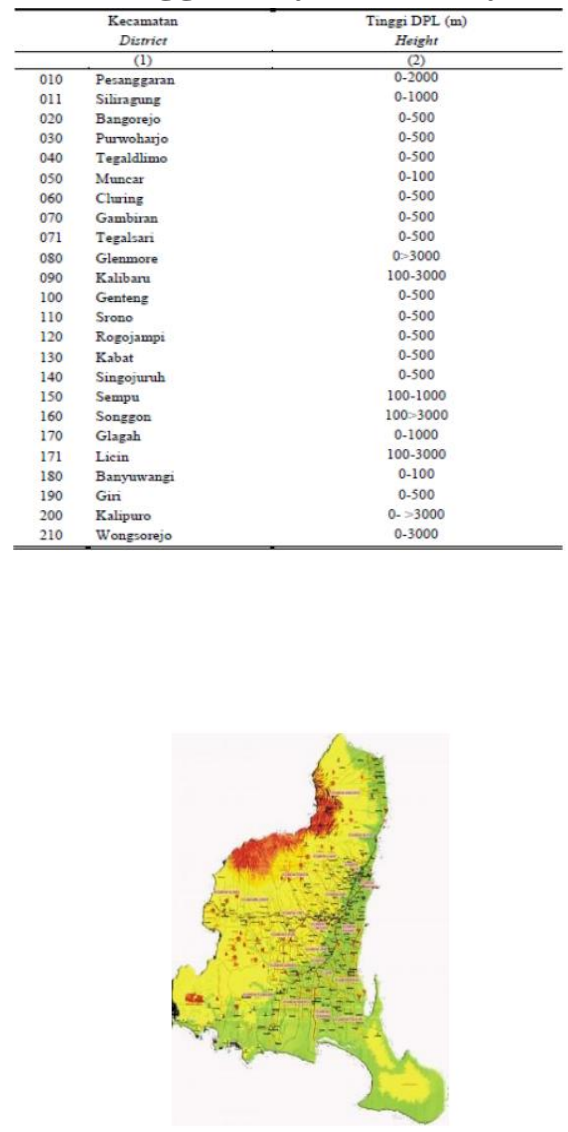

Gambar 1. Peta Kabupaten Banyuwangi (Anonim, 2014)

3. Metode Penelitian 


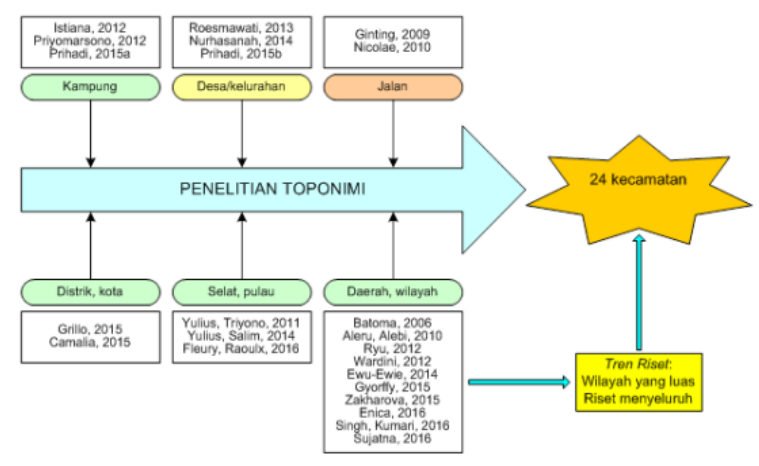

Penelitian direncanakan mulai awal tahun 2018 di wilayah kabupaten Banyuwangi. Pengambilan data, dilakukan dengan wawancara dengan 3 nara sumber yaitu 1 sumber pemerintahan kecamatan dan 2 tokoh masyarakat setempat. Validasi data dengan metode triangulasi 3 nara sumber. Pengelompokkan data berdasarkan karakteristik toponimi. Penyusunan hasil pengolahan data.

Pengambilan dilakukan dengan wawancara. Wawancara pertama dilakukan dengan pihak pemerintah setempat. Tokoh masyarakat dipilih berdasarkan informasi yang didapat dari pemerintah setempat. Wawancara dilakukan oleh 3 tim dimana 1 peneliti didampingi 1 tenaga survei. Proses wawancara dilengkapi dengan alat perekam dan dokumentasi menggunakan kamera. Informasi hasil wawancara dilakukan validasi dengan metode triangulasi 3 sumber. Hasil validasi selanjutnya disusun dalam bentuk kategori informasi yang bersesuaian. Pengkategorian ini dilakukan untuk mendapatkan komposisi pola penamaan. Hasil analisis disusun menjadi buku toponimi dalam bentuk narasi deskriptif.

4. Hasil dan Pembahasan

\subsection{Asal Usul Banyuwangi}

Asal-usul pemberian nama tersebut ada hubungannya dengan cerita legenda Sidopekso Of Sritanjung yang artinya bahwa dulunya ada seorang raja yaitu Prabu Sulahkromo memiliki patih yang bernama Sidopekso yang memiliki istri cantik yang bernama putri Sritanjung,karena sang raja mengagumi kecantikan sang putri Sritanjung dan suka terhadap istri sang patih tersebut sehingga raja mengutus sang patih untuk pergi berperang yang tujuannya agar sang raja bisa merayu putri sritanjung namun sang putri tidak tergoda dengan rayuan sang raja.Putri Sritanjung merasa bahwa dia harus tetap setia menunggu sang patih yang pergi ke medan perang dikemudian hari sang patih kembali ke kerajaan untuk melaporkan bahwa perang sudah usai dan kerajaan nya memenangkan pertempuran,namun karena sang raja merasa sakit hati karena cintanya ditolak oleh putri Sritanjung sehingga raja memfitnah putri Sritanjung dengan mengatakan bahwa selama sang patih pergi berperang istrinya merayu sang raja yang akhirnya membuat sang patih marah terhadap istrinya dan menuduhnya berselingkuh.

Putri Sritanjung menanggapi kemarahan suaminya dengan sabar dan menjelaskan bahwa dia tidak berselingkuh dengan sang raja,namun sang raja yang mencoba 
merayunya tapi karena sang patih Sidopekso sudah terbawa emosi dan tidak mendengarkan penjelasan dari putri Sritanjung, yang akhirnya patih Sidopekso berencana ingin membunuh istrinya di sebuah sungai yang keruh.Niat jahat tersebut diketahui oleh putri Sritanjung namun sang putri berpesan kepada suaminya sebelum meninggal bahwa jika sang Patih membunuhnya dan darah yang dikeluarkan sang putri berbau harum maka membuktikan bahwa dia tidak berselingkuh dengan sang Raja namun jika darah yang dikeluarkan berbau busuk itu berarti sang putri berselingkuh dengan sang Raja.Namun katakata yang di ucapkan putri Sritanjung tidak membuat sang patih tersadar namun membuat sang patih semakin bertambah marah dan langsung membunuh putri Sritanjung dengan menusukkan keris yang sangat tajam di dada sang istri dan jasadnya di buang ke sungai.

Jasad dari Putri Sritanjung yang di buang ke sungai mengeluarkan darah yang membuat air sungai yang keruh berubah menjadi bening seperti kaca dan mengeluarkan aroma harum dari sungai tersebut.Dan hal tersebut membuat Patih Sidopekso menyesal dan menyadari kesalahannya bahwa sesungguhnya istrinya tidak berselingkuh,dari legenda tersebut muncullah asal usul nama kota Banyuwangi (Banyu=Air,Wangi=Harum).

Jadi kesimpulannya menurut narasumber kenapa kecamatan kota dinamakan Kecamatan Banyuwangi Kota adalah merupakan bentuk apresiasi masyarakat Banyuwangi terhadap legenda asal usul kota Banyuwangi yang sudah banyak di ketahui masyarakat Banyuwangi.

\subsection{Asal Usul Singojuruh}

Desa Singojuruh, Kecamatan Singojuruh, Kabupaten Banyuwangi yang merupakan suatu desa yang terletak disebelah selatan kota Banyuwangi. Luas Desa Singojuruh kurang lebih 503,0 Ha. Luas lahan tersebut dapat dibagi menjadi dua pokok luas lahan diantaranya yaitu luas lahan pertanian dan luas lahan pemukiman. Untuk luas lahan pertanian atau tanah sawah di desa Singojuruh mencapai luas 306,00 Ha lahan tersebut merupakan lahan sawah irigasi teknis, sedangkan untuk luas lahan pemukiman atau tanah kering dibagi menjadi beberapa diantaranya Tegal/ladang $\quad 8,30 \quad \mathrm{Ha}$ Pemukiman 136,00 Ha Pekarangan $32,20 \mathrm{Ha}$ sehingga mencapai Total luas $176,50 \mathrm{Ha}$. 
sejarah adanya Desa Singojuruh tentu harus melihat atau mengenang ulang sebelum sejarah kemerdekaan, sebuah tempat/desa yang masyarakat didalamnya menyebut dengan Desa Karangsari. Sebutan tersebut tentu mempunyai alas an yang kuat sebelum menjadi Desa Singojuruh. Dengan berdirinya pohon beringin yang terletak di tanah PJKA yang gandengan dengan pasar. Dari sanalah kemudian sejarah desa berkembang hingga akhirnya desa yang semula masyarakat menyebut Karangsari beralih dengan sebutan Singojuruh. Di jaman kemerdekaan pada tahun 1945, Desa Singojuruh merupakan desa yang amat potensial. Sedangkan dilihat dari asal kata Singojuruh yang berarti "Singo" adalah singa/macan dan "Juruh" adalah petunjuk, yang berarti bahwa Singojoruh adalah seekor singa yang menunjukkan adanya tempat yang kemudian bernama Singojuruh yang kini menjadi desa. Lalu Desa Singojuruh berkembang menjadi 9 Dusun sebagai wujud dari kemudahan dalam menata kondisi sosial masyarakat dalam $\mathrm{p}$ elayanan ataupun guna untuk mempermudah dalam mengordinir dan membangun desa
4.3 Asal Usul Rogojampi

Desa Rogojampi adalah sebuah Desa yang terletak di Pusat kota wilayah Kecamatan Rogojampi Kabupaten Banyuwangi, tepatnya berada pada posisi pusat pemerintahan Kecamatan Rogojampi, dengan batas - batas Utara Desa Karangbendo Kecamatan Rogojampi dan Desa Gitik Kecamatan Rogojampi, Sebelah Timur Desa Watukebo Kecamatan Rogojampi, Sebelah Barat Desa Rogojampi Kecamatan Rogojampi dan Desa Lemahbangdewo Kecamatan Rogojampi, Sebelah Selatan Desa Desa Kedaleman Kecamatan Rogojampi dan Desa Kaotan Kecamatan Rogojampi

Luas wilayah Desa Rogojampi 279 Ha, dengan penggunaan sebagai berikut, tanah permukiman 2,89\%, Untuk bangunan : perkantoran 0,034 \% ,Sekolahan 0,43\%, pertokoan 0,094 \% , Masjid 0,54\%, Kuburan 0,41 \%, Jalan 1,48 \%, Pertanian Sawah $65 \%$, Ladang /tegal $27,77 \%$, Olah raga $0,12 \%$, Tambak $0,0034 \%$ dan penggunaan lain- lain 1,10\%.

Pada tahun 1895 sampai 1915 Desa Rogojampi di pimpin oleh seorang Kepala Desa yang ditunjuk dari Pemerintah Kabupaten yang dikenal dengan Government untuk menjalankan segala aktivitas pemerintahan. Konon pada saat itu 
di Desa Rogojampi masih belum ada masyarakat yang bisa melaksanakan tuga dan tanggung jawab di bidang pemerintahan karena mayoritas penduduk DesaRogojampi merupakan penduduk fanatis terhadap agama islam khususnya, sehingga kepala desa yang ditugaskan dari kabupaten bersama masyarakat membangun Desa Rogojampi ini sedikit demi sedikit sesuai dengan peraturan - peraturan yang ada.

Aleru JO, Alebi RA, 2010, Towards a Reconstruction of Yoruba Culture History: a Toponymic Perspective, African Study Monographs, 31(4): 149-162

Anonim, 2014, Kabupaten Banyuwangi, http://www.infobanyuwangi.com, diakses tanggal 14 Maret 2017

Atasoy E, Yeginbayeva A, 2017, Toponymic Approach in Scientific Research of Landscapes Associated With the Plant World, International Conference on Literature, Humanities and Social Sciences (LHSS-17): 21-27

Badan Pusat Statistik kabupaten Banyuwangi, 2013, Banyuwangi Dalam Angka Tahun 2013

Batoma A, 2006, African Ethnonyms and Toponyms: An Annotated Bibliography, Electronic Journal of Africana Bibliography 10: $1-40$

Bugybaykizi BZ, Ushtanovna ZL, Rahmetovna KA, Tileubergenovna SS,
Akzholovich BT, Ongarbekovna BG, 2015, Ethnographi Development of Kazakh Toponymy, Mediterranean Journal of Social Sciences 6(4)S1: 462-466

Camalia M, 2015, Toponimi Kabupaten Lamongan (Kajian Antropologi Linguistik), Parole 5(1): 74-83

Curchin LA, 2011, Naming the Provincial Landscape: Settlement And Toponymy in Ancient Catalunya, Hispania Antiqua XXXV: 301-320

Enica S, 2016, Toponymic Strata on the Dobrogea Bank of the Danube Seen from a Historic and Multicultural Perspective, Journal of Danubian Studies and Research 6(1): 370-384

Fleury C, Raoulx B, 2016, Toponymy, Taxonomy and Place, Explicating the French concepts of presqu'île and peninsula, Shima: The International Journal of Research into Island Cultures 10(1): 8-20

Ginting DA, 2009, Sejarah Pergantian Nama Jalan di Kota Medan (1900-1970), Skripsi, Departemen Sejarah, Fakultas Sastra, Universitas Sumatera Utara, Medan

Grillo H, 2015, Toponymy as Macrostructure and Microstructure (Study on the Toponymy of the Himara District), Proceedings of ICONN 3: 495-503

Györffy E, 2015, The Toponymic Competence: a Case Study in the Hungarian Settlement Tépe, Вопросы ономастики 2 (19): $83-100$ 
Helleland B, 2012, Place Names and Identities, Oslo Studies in Language 4(2): 95-116

Istiana, 2012, Bentuk dan Makna NamaNama Kampung di Kecamatan Kotagede, Skripsi, Program Studi Bahasa dan Sastra Indonesia, Fakultas Bahasa dan Seni, Universitas Negeri Yogyakarta

Nicolae I, 2010, Camino De Santiago Place Names and Street Names as Border Posts in the Collective Memory (I), Human Geographies - Journal of Studies and Research in Human Geography 4(1): 17-31

Nurhasanah, Wahya, Sunarni N, 2014, The Name of six Villages at Situraja District Sumedang Regency (Ethnolinguistic Study), International Journal of English and Education 3(3): 3339

Owu-Ewie C, 2014, A Morphosyntactic Analysis of Some Fante Habitation Names (Econym), The International Journal Of Humanities \& Social Studies 2(5): 232243

Prihadi, 2015a, Struktur Bahasa Nama Pedusunan (Kampung) di Daerah Istimewa Yogyakarta: Kajian Antropolinguistik, Litera 14(2): 307-316

Prihadi, 2015b, The Cultural Background of Toponim System of Hamlets/Villages in Yoyakarta Special Province (an Antropolinguistic Study), Research on Humanities and Social Sciences 5(6): 96103

Priyomarsono MW, 2012, Historical Review of "Kampung" Baluwerti in Keraton
Palace as "Evidence" of Java Villages' Development in Surakarta, Journal of US-China Public Administration 9(9): 10841096

Roesmawati A, 2013, Sistem Penamaan Kelurahan di Kota Probolinggo (Kajian Tradisi Lisan), Skripsi, Program Studi Pendidikan Bahasa dan Sastra Indonesia, Jurusan Pendidikan Bahasa dan Seni, Fakultas Keguruan dan Ilmu Pendidikan, Universitas Jember

Ryu J-H, 2012, A Cultural History of Korean Toponyms, Korea Journal/Spring 2012: 5-10

Singh V, Kumari L, 2016, Toponymy or the Geography of Place-Names in the Aravalli Hills and Semi-Arid Plains of Rajasthan, RNI Periodic Research V(2): 4448

Sujatna ETS, Heriyanto, Pamungkas K, 2016, Place-Naming of Tourism Destinations in Jawa Barat: A Toponymy Study, Ijasos - International E-Journal of Advances in Social Sciences II(5): 471-476

Taqyuddin, 2016, Punahnya Toponimi Indikasi Erosi Bahasa dan Punahnya Bangsa, Makalah, Seminar Nasional Toponimi "Toponimi dalam Perspektif Ilmu Budaya, FIB-UI, https://www.staff.blog.ui.ac.id, diakses tanggal 14 Maret 2017

Wardini E, 2012, Some Aspects of Aramaic as Attested in Lebanese Place Names, Orientalia Suecana LXI Suppl: 2129 